\title{
The Characteristics of Hospitalized Pneumonia Patients among Malaysian Hajj Pilgrims
}

\author{
Nurul Diana Dzaraly', Nor Iza A. Rahman'", Mainul Haque², Nordin Bin Simbak', Mohd Suhaimi Abdul Wahab³, Aniza Abd Aziz', \\ Mohd Shafie Abdulllah ${ }^{3}$, Irfan Mohamad ${ }^{3}$, Abdul Razak Abdul Muttalif', Salwani Ismail', Shaharudin Abdullah ${ }^{5}$ \\ ${ }^{1}$ Faculty of Medicine, Universiti Sultan Zainal Abidin (UniSZA), 20400 Kuala Terengganu, Terengganu, Malaysia. \\ ${ }^{2}$ Faculty of Medicine and Defense Health, National Defence University of Malaysia, Kem Sungai Besi, 57000 Kuala Lumpur, Malaysia. \\ ${ }^{3}$ School of Medical Sciences (PPSP), Hospital Universiti Sains Malaysia (HUSM), 16150 Kubang Kerian, Kelantan, Malaysia. \\ ${ }^{4}$ Institute of Respiratory Medicine, Hospital Kuala Lumpur, Jalan Pahang, 50586 Kuala Lumpur, Malaysia. \\ ${ }^{5}$ Consultant of Internal Medicine (Respiratory Medicine), Institute of Respiratory Medicine, Hospital Kuala Lumpur, Jalan Pahang, 50586 Kuala Lumpur, Malaysia.
}

\begin{abstract}
Background: Hajj is the largest annual gatherings in the Islamic world. Hajj pilgrims encounter a great deal of heavy physical and mental stress. Chest infection, especially pneumonia is a potentially life-threatening illness which poses global health problems, particularly among elderly performing hajj. The objective of this study was to identify the sociodemographic, clinical and laboratory characteristics of patients clinically suspected of having pneumonia during Hajj season. Methods: A cross-sectional study was conducted on Malaysian hajj pilgrims who were admitted to Tabung Haji (medical center) in Makkah with clinical diagnosis of pneumonia. The relevant patient's data were recorded from the hospital information system. Results: A total number of 157 Hajj pilgrims clinically diagnosed as pneumonia were recruited during the 2012/2013 Hajj season. Pneumonia affected male more than females $(55.4 \%$ and $44.6 \%)$, with a mean age of $69.4(10.0)$ years. Coughing $(96.2 \%)$ was recorded as the commonest symptoms followed by fever $(84.7 \%)$ and breathlessness $(47.1 \%)$. Most of the pilgrims were noted to have hypertension $(60.5 \%)$ while $28.0 \%$ of them had diabetes, chronic obstructive pulmonary disease $(25.5 \%)$ and asthma $(12.7 \%)$. The laboratory finding showed mean white blood cell count was 16.9 (13.0) $\times 10^{\circ} \mathrm{L}$, and the neutrophils differential count was $81.1 \%$ (15.5). The most frequently prescribed antibiotic is levofloxacin $(54.8 \%)$, followed by azithromycin $(39.2 \%)$ and cefuroxime $(23.6 \%)$. The mean length of hospital stay was $4.17( \pm 3.13)$ days, and most of the patients $(97.5 \%)$ were discharged after getting treatment. Conclusion: The current study found that elderly males were the main sufferers of bronchopneumonia after Wuquf with an average length of stay $4.17 \pm 3.13$. Moreover, levofloxacin was found to be most effective antibiotic.
\end{abstract}

Key words: Hajj, Pneumonia, Pilgrims, Clinical manifestation, Laboratory findings.

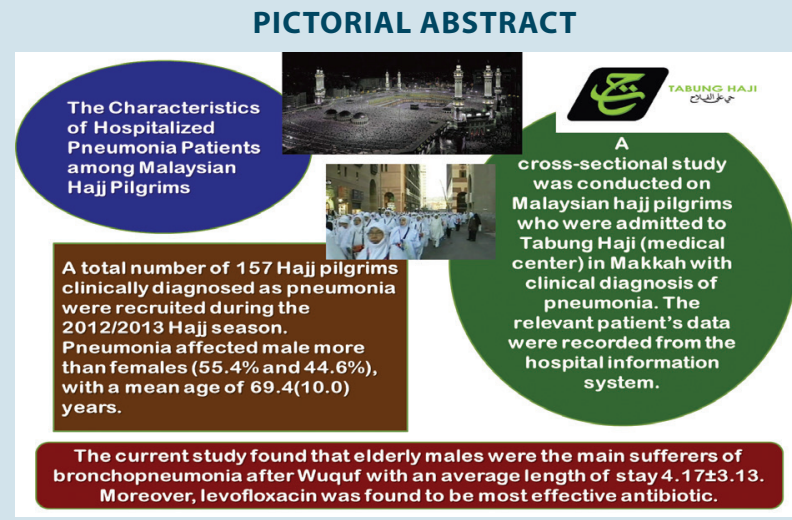

Correspondence :

Nor Iza A. Rahman

Senior Medical Lecturer, Faculty of Medicine, UniSZA, 20400 Kuala Terengganu, Terengganu, Malaysia.

E-mail: noriza@unisza.edu.my

DOI: 10.5530/jyp.2016.3.20

\section{INTRODUCTION}

Globally, Hajj is the largest and longest standing annual Muslim mass gatherings for religious and ritual performances which is performed in Makkah, Kingdom of Saudi Arabia (KSA). ${ }^{1}$ Every year, more than 2.5 million Muslims from different parts of the world perform Hajj. ${ }^{2}$ The gathering of Hajj pilgrims from various countries around the world for over a month's time, which inevitably causes overcrowding and confinement leading to a number of public health challenges. ${ }^{3}$ As pilgrims encounter extreme 'physical exhaustion, extreme heat, and crowded accommodation encourage disease transmission, especially of airborne agents. ${ }^{4}$ Moreover, due to the very high thickness of pilgrims and the distance from one another remain very close and less than three feet, which promote infectious diseases to be transmitted among Hajj pilgrims. ${ }^{3}$ Respiratory tract infections are the commonest ailment among Hajj pilgrims, and the primary cause of hospitalization and pneumonia was found to be top of the list. ${ }^{5,6}$ Community-acquired pneumonia (CAP) is a common and potentially life-threatening illness and remains as one of the global public health challenges and leading cause of death. ${ }^{7,8}$ Pneumonia remains as a life threatening disease among elderly Hajj pilgrims. ${ }^{8}$ Among CAP, Pneumococcal pneumonia is one of the most common bacterial disease need to be addressed by the clinicians. ${ }^{9}$ It was considered as a significant source of morbidity and mortality throughout the worldwide. ${ }^{10}$

The clinical pneumonia is characterized by a variety of symptoms and signs that depend on types of pathogen causing infection, age and overall health. ${ }^{11}$ The previous studies have identified the typical symptoms of CAP. ${ }^{12-16}$ Patients with pneumonia often have a productive cough, followed by an abrupt onset of fever, chills, or rigors, shortness of breath, hypoxia, malaise, weakness, sharp or stabbing chest pain during deep breaths and an increased rate of breathing. ${ }^{12-16}$ Confusion is the most prominent sign among elderly. ${ }^{12,16,17}$ Generally, underlying diseases such as diabetes, HIV infection, renal failure, cancers, respiratory failure, malnutrition and treatment with immunosuppressive drugs are identified as the risk factors for pneumonia. ${ }^{18}$ Commonly, pneumonia is diagnosed based on clinical features. ${ }^{19}$ The diagnostic tools are used to substantiate the clinical diagnosis, to find the etiology and look for severity and complications. Chest radiographs, full blood count (FBC), blood culture and sputum culture are recommended as the diagnostic tools for routine evaluation as well as to identify the bacteria or other microorganisms that cause pneumonia infection. All this diagnostic methods are available at the Tabung Haji (TH), which commonly performed for the suspected 
patient of having pneumonia. TH is the key organization of the Malaysian Government for Malaysian Hajj Pilgrims Healthcare during the Hajj time in Saudi Arabia. Pilgrims Fund Board (Lembaga Tabung Haji) or the more popular for Malaysian citizens as TH was first established on 30 September 1963 under the name "Malayan pilgrims saving corporation" which run by Malaysian government itself. ${ }^{20}$ Its establishment was proposed by Royal Professor Ungku Aziz based his research on "Pilgrims Economy Improvement Plan in $1959 .{ }^{20}$ Every year, 26,000 Malaysian Hajj travel to Makkah to perform Hajj and they are managed by $\mathrm{TH}$. In terms of medical facilities, there are three main Health Centre in Makkah managed by TH, which provides health care for Malaysian Hajj pilgrim's, namely Aziziah Medical Centre ( 80 beds), Syisya Medical Centre (98 beds) and Pusat Al-Janadriah Medical Centre (41 beds). ${ }^{21}$ Both Syisya and Aziziah medical centers are wholly owned by the TH medical center where the management was fully supported by the Ministry of Health of Government of Malaysia. They are considered as major health centers, which provide patient treatment by trained staff and equipped with medical instruments and medications. The Syisya Medical Centre mostly cared for respiratory infection cases; hence, the majority of Hajj pilgrims was admitted to this medical center compared to Aziziah Medical Centre. The empirical antibiotic treatment has been recommended for all suspected CAP as an initial treatment which is based on prevalence of the pathogen and local antibiotic resistance profiles. ${ }^{22}$ This research is intended to describe the clinical manifestation and laboratory findings among patients with clinically suspected pneumonia. The results could serve as baseline data in determining the pattern of characteristic of patients mainly Malaysian Hajj pilgrims hospitalized with pneumonia.

\section{MATERIALS AND METHODS}

\section{Study Design and Patient Population}

A cross-sectional study was conducted on Malaysian Hajj Pilgrims (age $\geq 18$ ) who was admitted to TH in Makkah presenting with the sign and symptoms of pneumonia. The study, focused on the Syisya Medical Centre and Aziziah Medical Centre. The study was conducted during Hajj season in October to November 2012 (1433H) and September to October $2013(1434 \mathrm{H})$. A total of 157 patients with clinical diagnosis of pneumonia were included as participants in this study.

\section{Study Procedure}

All patients who have symptoms and signs of pneumonia were admitted to TH hospitals. As the number of the study population was small, so Universal Sampling was adopted. The clinical diagnosis of pneumonia was made based on the clinical manifestations as well as chest radiograph findings. The demographic data, past medical history, pneumococcal vaccination status, clinical manifestations, investigations and management of the patients were recorded in a case record form. The suspected cases of pneumonia among Hajj pilgrim, during the Hajj season, who was admitted to the $\mathrm{TH}$ with or without the presence of underlying comorbidity were included in the study.

\section{Statistical Analysis}

The Statistical Package for the Social Science (SPSS) version 20.0 was used for data entry and statistical analyses. Descriptive statistics were applied to assess the baseline characteristics in terms of clinical manifestation and laboratory diagnosis of whom was admitted to the $\mathrm{TH}$ medical centers.

\section{Ethical Approval}

The official ethical approval was obtained from the Ministry of Health Research and Ethics Committee Malaysia (MREC) with the reference number, NMRR-14-1177-21761 (IIR) dated $19^{\text {th }}$ December 2014. The informed written consent was obtained for utilization of the data for research purpose from every subject involved in this study.

\section{RESULTS}

\section{Socio-Demographic Characteristics of Respondents}

A total of 157 respondents with the clinical diagnosis of pneumonia were recruited from TH medical centers during the hajj season (2012 and 2013) for this study. Males appeared to be affected more often compared to females $(55.4 \%(n=87)$ and $44.6 \%(n=70)$ respectively, with a mean (SD) age of 69.4 ( \pm 10 ) years, ranging from 33 to 88 years. The distribution for the state of origin were from Johor (17.8\%), followed by Selangor (12.7\%), Kedah (11.5\%), Kelantan (10.8\%), Perak (10.2\%), Pulau Pinang (7.0\%), Terengganu (6.4\%), Pahang (6.4\%), Negeri Sembilan (4.5\%), Sabah (3.8\%), Sarawak (3.2\%), Kuala Lumpur (3.2) and Melaka (2.5\%). The majority of respondents was admitted to the Syisya Medical Centre with the percentage of $98.1 \%$ compared to Aziziah Medical Centre (1.9\%) (Table 1).

\section{Clinical Characteristics}

Seventy-six point four percent (120) of the patients was admitted to the TH hospitals after Wukuf. The Wukuf is the second obligatory acts of Hajj is in Arafat. Wukuf is known as "Standing before God" and one of the most very significant rituals of Hajj. "Arafat" is a desert about $20 \mathrm{~km}$ from Makkah, which has become semi-treed today and it is obligatory for Hajj pilgrims to stay at the Plain of Arafat, on the ninth day of Dhu'lHijjah (the Possessor of the Pilgrimage or The Month of the Pilgrimage). An enormous gathering of Hajj pilgrims at the Plain of Arafat. ${ }^{23}$ The majority of pneumonia patients were non-smokers (81.5\%), with only $3.2 \%$ of patients were smokers while $15.3 \%$ were former smokers. As for pneumococcal vaccination, only $21 \%$ of the Malaysian Hajj pilgrims received pneumococcal vaccines namely pneumococcal polysaccharide vaccine. More than half of the patients are hypertensive $(60.5 \%)$ while $28.0 \%$ of the patient have diabetes, followed by chronic obstructive pulmonary disease (COPD) (25.5\%), asthma (12.7\%), ischemic heart disease (11.5\%) and heart failure (5.7\%). The majority (96.2\%) of the respondents complained of having cough symptoms during Hajj season while more than half of them $(84.7 \%)$ noted to have fever and half of respondents $(47.1 \%)$ were having difficulty in breathing during Hajj activities. Basically, most of the respondents were having more than one of the presenting symptoms and underlying disease. $54.3 \%$ of patients were diagnosed as having bronchopneumonia, and the rest (45.7\%) was classified as having lobar pneumonia. The mean length of stay among hospitalized respondents was $4.17 \pm 3.13$ days, and most of the respondents were discharged (97.5\%) after getting treatment, and $2.5 \%$ of them had to be transferred to Arab hospitals (Table 2).

\section{Laboratory Characteristics}

The mean white blood cell count (WBC) on admission was 16.9 $(13.0) \times 10^{9} / \mathrm{L}$ with one missing value while the average of the neutrophils differential count was 81.1 (15.5)\% with nine missing values and $10.9(12.0) \%$ of the lymphocyte count mean with nine missing values (Table 3 ). The culture of the sputum and blood samples was carried out in accordance to the standard of microbiological method to detect the specific causative agents of pneumonia and the results are shown in Table 4. Pathogens were isolated in only $4.6 \%$ of the sputum culture. The pathogens isolated were as follows: Pseudomonas aeruginosa (42.9\%), Klebsiella pneumoniae (28.6\%) and Streptococcus pneumoniae (28.6\%). Only $3.2 \%$ of blood culture were performed among pneumonia patient and none of culture obtained pathogen isolated (Table 4). 
Table 1: The socio-demographic characteristic of patients with having pneumonia $(n=157)$

\begin{tabular}{cccc}
\hline Variables & Frequency & Percentage (\%) & Mean (sd) \\
\hline Gender & & & \\
Male & 87 & 55.4 & \\
Female & 70 & 44.6 & \\
Age & & & \\
Hospital admission & & & \\
Syisya Medical Centre & 154 & 98.1 \\
Pusat Rawatan Aziziyah & 3 & 1.9 \\
States & & & \\
Johor & 28 & 17.8 \\
Selangor & 20 & 12.7 \\
Kedah & 18 & 11.5 \\
Kelantan & 17 & 10.8 \\
Perak & 16 & 10.2 \\
Pulau Pinang & 11 & 7.0 \\
Terengganu & 10 & 6.4 \\
Pahang & 10 & 6.4 \\
Negeri Sembilan & 7 & 4.5 \\
Sabah & 6 & 3.8 \\
Sarawak & 5 & 3.2 \\
Kuala Lumpur & 5 & 3.2 \\
Melaka & 4 & 2.5 \\
Total & 157 & \\
\hline & & \\
\hline
\end{tabular}

\section{Antibiotic Therapy}

The pattern of antibiotic therapy is given to Malaysian Hajj pilgrims who were admitted to $\mathrm{TH}$ medical centers for pneumonia are illustrated in Table 5. Based on the current study, the most frequently prescribed antibiotic was levofloxacin $(54.8 \%)$, followed by azithromycin (39.2\%), cefuroxime (23.6\%), ceftriaxone (14.6\%), cefepime $(14.0 \%)$, amoxicillin+clavulanate (14.0\%) and ampicillin+sulbactam (10.8\%). Meropenem (1.3\%), ciprofloxacin (1.3\%), erythromycin ethyl succinate $(2.5 \%)$ and were least prescribed (Table 5).

\section{DISCUSSION}

In terms of gender, the study results illustrated that male respondents were slightly higher in number (55.4\%) when compared to female $(44.6 \%)$. Although a smaller gap proportion of gender has been obtained through this study, the similar findings noted in the previous study that pneumonia most frequently occurred in males. ${ }^{3}$ In general, men are usually responsible for taking great care of their family since they are physically fit and tough pilgrims. The majority of women or elderly pilgrims will assign men pilgrims during Ramī Aj-Jamarāt (The Stoning of the Devil) ritual. ${ }^{24}$ The mean age of Malaysian Hajj pilgrims who developed pneumonia during Hajj 1433/1434H season was 69.4 (10.0) years. The majority of Malaysian Hajj pilgrims were in the elderly, which is consistent with previous studies conducted on clinical and temporal patterns of severe pneumonia causing critical illness in Hajj pilgrims, which had revealed the mean age was rather similar to our study, that was $64( \pm 12)$ years. ${ }^{25}$ Most of the pneumonia patients were admitted in Syisya Medical Centre (98.1\%) compared to Aziziah Medical Centre (1.9\%). In this study, The majority hospital admission for pneumonia among studied
Table 2: The clinical findings of respondents $(n=157)$

\begin{tabular}{|c|c|c|c|}
\hline Variable & Frequency & Percentage (\%) & $\begin{array}{c}\text { Mean } \\
\text { (sd) }\end{array}$ \\
\hline \multicolumn{4}{|l|}{ Admission } \\
\hline Before Wuquf & 37 & 23.6 & \\
\hline After Wuquf & 120 & 76.4 & \\
\hline \multicolumn{4}{|l|}{ Smoking status } \\
\hline Smoker & 5 & 3.2 & \\
\hline Former smoker & 24 & 15.3 & \\
\hline Non smoker & 128 & 81.5 & \\
\hline \multicolumn{4}{|l|}{ Status of pneumococcal vaccines } \\
\hline Taken Pneumo 23 & 33 & 21.0 & \\
\hline Not taken & 124 & 79.0 & \\
\hline \multicolumn{4}{|l|}{ Underlying diseases } \\
\hline Hypertension & 95 & 60.5 & \\
\hline Diabetes & 44 & 28.0 & \\
\hline COPD & 40 & 25.5 & \\
\hline Asthma & 20 & 12.7 & \\
\hline Ischemic Heart Disease & 18 & 11.5 & \\
\hline Congestive heart failure & 9 & 5.7 & \\
\hline Bronchiectasis & 4 & 2.5 & \\
\hline Multiple myeloma & 2 & 1.3 & \\
\hline Benign prostate hypertension & 1 & 0.6 & \\
\hline Neurofibromatosis & 1 & 0.6 & \\
\hline \multicolumn{4}{|l|}{ Symptoms and duration } \\
\hline Fever & 133 & 84.7 & \\
\hline Duration of fever & & & $\begin{array}{c}3.8 \\
(2.4)\end{array}$ \\
\hline Cough & 151 & 96.2 & \\
\hline Duration of a cough & & & $\begin{array}{c}4.5 \\
(2.4)\end{array}$ \\
\hline Breathlessness & 74 & 47.1 & \\
\hline Duration of Breathlessness & & & $\begin{array}{c}1.4 \\
(2.0)\end{array}$ \\
\hline \multicolumn{4}{|l|}{ Chest X-ray } \\
\hline Bronchopneumonia & 76 & 54.3 & \\
\hline Lobar pneumonia & 64 & 45.7 & \\
\hline Length of hospital stay & & & $\begin{array}{c}4.17 \\
(3.13)\end{array}$ \\
\hline \multicolumn{4}{|l|}{ Outcomes } \\
\hline Discharge & 153 & 97.5 & \\
\hline Transfer to Arab hospital & 4 & 2.5 & \\
\hline
\end{tabular}

Hajj pilgrims were after Wakuf. The overcrowding of pilgrims in confined area and close inter pilgrims contact, especially in Hajj camps of Mina is an ideal ground for the spread of respiratory diseases. ${ }^{26}$ Smoking status was categorized into three different groups; smoker, former smoker and non-smoker. The percentage of smokers among the pilgrims were $3.2 \%$, followed by $15.3 \%$ of the former smoker and $81.5 \%$ of a nonsmoker. The patterns of smoking status in our study showed that the majority of Malaysian Hajj pilgrims were non-smokers. The mean age for Malaysian Hajj pilgrims was 69.4 ( \pm 10.0 ) years, smoking prevalence basically was highest in the $25-34$ age group (25\%) and lowest amongst 
Table 3: The laboratory findings of respondents $(n=157)$

\begin{tabular}{cccc}
\hline Variables & Frequency & Percentage (\%) & Mean (sd) \\
\hline Laboratory findings & & & \\
White blood cell (WBC) & & & $16.9(13.0)$ \\
Normal & 34 & 78.2 & \\
High WBC & 122 & & $81.1(15.5)$ \\
Neutrophils & & 12.1 & \\
Normal neutrophils & 18 & 84.5 & \\
High neutrophils & 125 & 3.4 & \\
Low neutrophils & 5 & & \\
Lymphocytes & & 6.1 & \\
Normal lymhphocytes & 9 & 7.4 & \\
High lymhphocytes & 11 & 86.5 & \\
Low lymhphocytes & 128 &
\end{tabular}

Note: ${ }^{a}$ Missing value $1{ }^{\mathrm{b}}$ Missing value 9.

Table 4: Result of sputum and blood cultures $(n=157)$

\begin{tabular}{ccc}
\hline Cultures & Frequency & Percentage (\%) \\
\hline Result of sputum culture & & \\
No pathogen isolated & 150 & 95.4 \\
Pathogen isolated & 7 & 4.6 \\
Klebsiella pneumoniae & 2 & 28.6 \\
Pseudomonos aeruginosa & 3 & 42.9 \\
Streptococcus pneumoniae & 2 & 28.6 \\
Result of blood culture & & \\
Perform blood culture & 5 & 3.2 \\
No pathogen isolated & 5 & 100 \\
\hline
\end{tabular}

Table 5: The pattern of antibiotic therapy of respondents $(n=157)$

\begin{tabular}{ccc}
\hline Variables & Frequency & Percentage (\%) \\
\hline Antibiotic therapy & 59 & 37.6 \\
Single antibiotic & 98 & 62.4 \\
Combination antibiotic & & \\
B lactam group & 22 & 14.0 \\
Amoxicillin+clavulanate & 17 & 10.8 \\
Ampicillin+sulbactam & & \\
Fluoroquinolones group & 2 & 1.3 \\
Ciprofloxacin & 86 & 54.8 \\
Levofloxacin & & \\
Cephalosporins group & 23 & 14.6 \\
Ceftriaxone & 22 & 14.0 \\
Cefepime & 37 & 23.6 \\
Cefuroxime & 9 & 5.7 \\
Ceftazidime & & \\
Macrolides group & 62 & 39.2 \\
Azithromycin & 4 & 2.5 \\
Tetracycline group & & \\
Doxycycline & & \\
Carbapenem group & & \\
Meropenem & & \\
\hline Erythromycin ethyl succinate (EES) & & \\
\hline & & \\
\hline
\end{tabular}


those aged 60 and over (11\%). ${ }^{27}$ To the best of our knowledge, none of the previous studies had discussed in details on pneumococcal vaccination Malaysian Hajj pilgrims. The current study found that only $21 \%$ of pilgrims were vaccinated with pneumococcal vaccines using pneumococcal polysaccharide vaccine. No-one has been vaccinated with pneumococcal conjugate vaccine. This finding indicates a low level of awareness on the importance of pneumococcal vaccination during Hajj season. Besides, in Malaysia, a meningococcal vaccine is the only compulsory vaccine for Hajj pilgrims. The importance of implementation of other important vaccines such as pneumococcal is highlighted especially among Malaysian pilgrims as to reduce the rate of pneumococcal pneumonia.

Hypertension and COPD were the commonest underlying disease identified among Malaysia Hajj pilgrims. The previous study has shown the similar finding which stated that lower respiratory tract infection was exacerbated by bronchial asthma and COPD and both were recognized as common underlying diseases in a patient admitted to hospital during Hajj (bronchial asthma-39.4\%, COPD-14.4\%). ${ }^{28}$ Moreover, diabetes and COPD were categorized as common underlying co-morbid conditions among elderly patients. ${ }^{28}$ Cough was determined as the most common symptom encountered by patients with pneumonia in the current study. This study's finding was in concordance with another study, which revealed a cough was categorized as one of the most common complaint among pilgrims as it has a very high attack rate during pilgrimage $(51 \%) .{ }^{29}$ Cough appears as one of the typical symptoms during Hajj due to overcrowding of the pilgrims from different countries around the world for a short and confined period, lead to a major public health challenge. ${ }^{3}$ Fever is also another common symptom identified in Malaysia Hajj pilgrims presented with pneumonia. Fever is also a typical symptom of pneumonia. ${ }^{30}$ Breathlessness was a least complained symptom among the Hajj pilgrims. It's often described as an intense tightening in the chest or feeling suffocation.

Based on chest radiograph findings, $54.3 \%$ of study patients were diagnosed as bronchopneumonia, and the rest (45.7\%) was lobar pneumonia. These results have been corroborated in another study regarding the correlation between clinical and chest radiographic diagnosis of pneumonia in Nigerian children, where most of them were diagnosed as bronchopneumonia (75.6\%) and followed by lobar pneumonia (21.6\%). ${ }^{31}$ The mean length of stay in hospitals in this study was $4.17( \pm 3.13)$ days. It was revealed that most of the pneumonia patients improve within 3 days of hospitalization with an appropriate antibiotic therapy. ${ }^{32}$ It can be concluded that most of the pneumonia patients admitted to the $\mathrm{TH}$ medical center have an optimum length of stay. This finding was also corroborated by other study which stated that the average duration of stay for pneumonia patients at Highland Hospital in 2011 was 4.47 days. ${ }^{33}$ The average length of stay for pneumonia in the USA was 5.4 days, according to the Healthcare Cost and Utilization Project Nationwide. ${ }^{34}$

The mean of WBC count of the respondents was noted to be high $\left(16.9 \times 10^{9} / \mathrm{L}\right)$ or known as leucocytosis which indicates the presence of inflammation or infection which can be due to viral or bacterial pathogens. ${ }^{35}$ High level of WBC was expected in pneumonia cases, and this was clearly shown by this study. The leucocytosis cases are represented by an increase in neutrophils, strongly suggested that the pneumonia was of the bacterial origin. Therefore, it's important to check the differential count when interpreting leucocytosis. In regards to the differential counts outcomes, mean of neutrophils had illustrated the high percentage of $81.1 \%$ (15.5). The increase of neutrophils count is known as neutrophilia where it is associated with any pathological condition that stimulates increased marrow production of neutrophils. All infection caused either by bacteria, viruses, fungi and parasites may lead to neutrophilia. However, the commonest cause is a bacterial infection. In viral infection, neutrophilia may occur in the early stage of infection. ${ }^{36}$
In our study, very low number of pathogens were isolated (4.6\%) during hajj season 2012 and 2013. This finding is in agreement with a study carried out on 450 patients who developed pneumonia during hajj season in 2009 and 2010, where positive sputum culture was found in only $7 \%$ of their patients based on laboratory hospital data. ${ }^{25}$ In contrast, based on a study done on 141 clinically diagnosed pneumonia in order to determine the specific pathogen isolated in sputum cultures, which was also carried out during hajj season, about half of the cases (53.9\%) were confirmed by culture result. ${ }^{3}$ Regarding the pattern of the organism isolated, result from sputum culture had illustrated that $P$. aeruginosa was the most frequent organism isolated (42.9\%) in pneumonia patient followed by K. pneumonia (28.6\%) and S. pneumoniae (28.6\%). Even though, $S$. pneumoniae was considered as a leading causative bacterium responsible for CAP, our study revealed a contradict outcome where $P$. aeruginosa was detected as the commonest pathogen. Generally, it was shown that the pattern was quite different as to compare to CAP cases occurred globally and this can be due to several factors contributed, including the decrease in cell-mediated immunity due to overcrowding, exhaustion and undernourishment. ${ }^{5}$

This study findings revealed that azithromycin and levofloxacin were the most frequently prescribed antibiotics among Malaysian Hajj pilgrims. Most of the respondents were often prescribed with levofloxacin (54.8\%), followed by followed by azithromycin (39.2\%). Levofloxacin is a broad spectrum antibiotic of the fluoroquinolone drug class and a levo isomer of its predecessor ofloxacin..$^{37}$ Levofloxacin plays a significant role in professional medical society guidelines for the treatment of pneumonia, urinary tract infection and abdominal infections, especially for grampositive and gram-negative bacterial pathogens. It is also recommended as a first-line treatment for CAP patients together with the presence of co-morbidities such as heart, lung, or liver disease. ${ }^{8}$ Azithromycin is a useful antibiotic for the treatment of bacterial infection (on specifically CAP) which is widely used alone or in combination with other antimicrobials. ${ }^{38-40}$

This study inevitably has several limitations. The sample size limitation. Initially, 169 respondents were included as an eligible participant, after going through the processes finally a total of 157 respondents was obtained. However, the total sample size still remained a suitable proportion after an additional of estimated drop-out rate of $10 \%$. The researchers experienced some constraints in conducting this study during Hajj season particularly time, limitation and several factors which could not be avoided. Researchers have only one month and a half to collect data and only two medical center recruitment were permitted. Nonetheless, 157 of the patients were manged to be recruited during that peak season.

\section{CONCLUSION}

The information on all variables of socio-demographic, clinical and laboratory characteristics was regarded as important valuable findings. None of the previous studies discussed the details of characteristic findings, particularly among Malaysian Hajj pilgrims who suffered from pneumonia during Hajj season. The current found that elderly males were the main sufferers of bronchopneumonia after Wuquf with an average length of stay $4.17 \pm 3.13$. Moreover, levofloxacin was found to be most effective antibiotic to cure Malaysian Hajj pilgrims. The current study advocated more research on this issue to safeguard the Malaysian Hajj Pilgrims.

\section{ACKNOWLEDGEMENT}

We wish to thank the Director-General of Health, Malaysia and MRECfor permission to conduct our study and subsequently the publication of this paper. We are greatly indebted to the Hospital Director and staff of the TH Hospital for their support and assistance in ensuring the success 
of this study, not forgetting the full cooperation of all participants and individuals for their invaluable support towards this study. Authors are much grateful to Mr Mohd Nor Faiz Zaman Pharmacy Executive, Ibu
Pejabat TH, 201 Jalan Tun Razak, 20400 Kuala Lumpur, Malaysia, and Mr Mohamad Hasrol Zainal, Programmer, Pivotal Infotech Sdn Bhd, 50450, Kuala Lumpur, Malaysia for their kind cooperation.

\section{CONFLICT OF INTEREST}

Authors do not posses financial or any other conflict of interest.

\section{ABBREVIATIONS USED}

KSA: Kingdom of Saudi Arabia; CAP: Community-acquired pneumonia; FBC: Full blood count; TH: Tabung Haji; SPSS: Statistical Package for the Social Science; MREC: Ministry of Health Research and Ethics Committee Malaysia; WBC: White blood cell count, COPD: Chronic obstructive pulmonary disease.

\section{ABOUT AUTHORS}

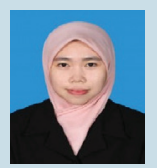

Nurul Diana Dzaraly, obtained her Diploma of Medical Laboratory Technologist in 2010 and Bachelor of Biomedical Science in 2012 from the Management and Science University (MSU). Her research interest is Medical Microbiology, Haematology and Infectious Disease. Recently, she just finished her Master of Science (Medical Microbiology).

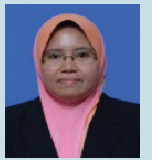

Dr. Nor Iza A Rahman is a Clinical Microbiologist who is recently appointed as the Head of Cluster of Advanced Medicine, Universiti Sultan Zainal Abidin (UniSZA), Kuala Terengganu, Malaysia. Previously, as the Head of School of Basic Medical Sciences, Faculty of Medicine (20092015), she had contributed a lot in curriculum development of Medicine Program in UniSZA. Her research interest are Medical Education, Medical Microbiology and Infectious Diseases.

\section{REFERENCES}

1. Shafi S, Booy R, Haworth E, Rashid H, Memish ZA. Hajj: health lessons for mass gatherings. J Infect Public Health. 2008;1(1):27-32.

2. Ebrahim SH, Memish ZA, Uyeki TM, Khoja TA, Marano N, McNabb SJ. Public health. Pandemic H1N1 and the 2009 Hajj. Science (New York, NY). 2009; 326(5955):938-40.

3. Asghar AH, Ashshi AM, Azhar El, Bukhari SZ, ZafarTA, Momenah AM. Profile of bacterial pneumonia during Hajj. Indian J Med Res. 2011;133(5):510-513.

4. Memish ZA. The Hajj: communicable and non-communicable health hazards and current guidance for pilgrims. Euro Surveill. 2010;15 (39): pii=19671. Available at: http://www.eurosurveillance.org/images/dynamic/EEN15N39/art19671. pdf Accessed on January 10, 2016

5. Alzeer AH. Respiratory tract infection during Hajj. Ann Thorac Med. 2009;4(2):50-3

6. Al-Ghamdi SM, Akbar HO, Qari YA, Fathaldin OA, Al-Rashed RS. Pattern of admission to hospitals during muslim pilgrimage (Hajj). Saudi Med J. 2003;24(10):1073-6.

7. Anevlavis S, Bouros D. Community-acquired bacterial pneumonia. Expert Opin Pharmacother. 2010;11(3):361-74

8. Mandell LA, Wunderink RG, Anzueto A, Bartlett JG, Campbell GD, Dean NC. Infectious Diseases Society of America/American Thoracic Society consensus guidelines on the management of community-acquired pneumonia in adults. Clin Infect Dis. 2007;44(Suppl 2):S27-72.

9. File TM. Community-acquired pneumonia. Lancet. 2003;362(9400):1991-2001.

10. Yoon HK. Changes in the epidemiology and burden of community-acquired pneumonia in Korea. Korean J Intern Med. 2014;29(6):735-7.

11. Centers for Disease Control and Prevention, (CDC). State-specific secondhand smoke exposure and current cigarette smoking among adults-United States, 2008. MMWR Morb Mortal Wkly Rep. 2009;58(44):1232-5

12. Stupka JE, Mortensen EM, Anzueto A, Restrepo MI. Community-acquired pneumonia in elderly patients. Aging Health. 2009;5(6):763-74.

13. Fernando J. Martinez. Monotherapy versus Dual Therapy for CommunityAcquired Pneumonia in Hospitalized Patients. Clin Infect Dis. 2004;38/Supplement 4):S328-S40

14. Lee JH, Ryu YJ, Chun EM, Chang JH. Outcomes and Prognostic Factors for Severe Community-Acquired Pneumonia that Requires Mechanical Ventilation. Korean J Intern Med. 2007;22(3):157-63

15. Ramirez JA, Anzueto AR. Changing needs of community-acquired pneumonia J Antimicrob Chemother. 2011;66(Suppl 3):iii3-9

16. Hoare Z, Lim WS. Pneumonia: update on diagnosis and management. BMJ. 2006;332(7549):1077-9.

17. Yoshikawa TT, Marrie TJ. Community-acquired pneumonia in the elderly. Clin Infect Diseases. 2000;31(4):1066-78.
18. American Thoracic Society. Pneumonia. Available at: https://www.thoracic.org/ patients/patient-resources/breathing-in-america/resources/chapter-15-pneumonia.pdf

19. Sethi S. Community-Acquired Pneumonia. MSD Manual, Professional Version. December 2014. Available at: http://www.msdmanuals.com/professional/ pulmonary-disorders/pneumonia/community-acquired-pneumonia

20. Manan AM. Hajj management of Malaysia. Research Paper -No. 40. First Edition. Islamic Research And Training Institute. Islamic Development Bank. 1996; 1-104. Available at: http://ierc.sbu.ac.ir/File/Book/ISLAMIC\%20SOCIOECONOMIC \% 20INSTITUTIONS\% 20AND\% 20MOBILIZATION\% 20OF\% 20 RESOURCES\%20WITH\%20SPECIAL\%20REFERENCE\%20TO\%20HAJJ\%20 MANAGEMENT\%20OF\%20MALAYSIA_47279.pdf Accessed on January 10, 2016

21. Tabung Haji. Perkhidmatan Pesakit Dalam Yang Disediakan 2014. Available at http://www.tabunghaji.gov.my/Accessed on January 10, 2016

22. Lim WS, Baudouin SV, George RC, Hill AT, Jamieson C, Le Jeune I. BTS guidelines for the management of community-acquired pneumonia in adults: update 2009. Thorax. 2009;64(Suppl 3):iii1-55

23. Wuquf in Arafat. Article 257. Available at: http://www.al-islam.org/rites-hajjpractical-treatise-and-rules-nasir-makarim-shirazi/wuquf-arafat

24. Alzahrani AG, Choudhry AJ, Al Mazroa MA, Turkistani AH, Nouman GS, Memish ZA. Pattern of diseases among visitors to Mina health centers during the Hajj season, 1429 H (2008 G). J Infect Public Health. 2012;5(1):22-34

25. Mandourah Y, Al-Radi A, Ocheltree A, Ocheltree S, Fowler R. Clinical and temporal patterns of severe pneumonia causing critical illness during Hajj. BMC Infect Dis. 2012;12(1):117.

26. Yousuf M. Pattern of respiratory disease among haj pilgrims visiting Madinah Al-Munawarah. Pak J Chest Med. 1999;5(4):7-10.

27. Robinson S, Bugler C. Smoking and drinking among adults, 2008. Genera Lifestyle Survey 2008. The Office for National Statistics (ONS). 2010; 1-78. Available at: file:///C:/Users/UDM/Downloads/glfsmokinganddrinkingamongadults200_tcm77-74228.pdf Accessed on January 10, 2016.

28. Gautret P, Soula G, Parola P, Brouqui P. Hajj pilgrims' knowledge about acute respiratory infections. Emerg Infect Dis. 2009;15(11):1861-2.

29. Ngozi NR, Chidinma O, Martin N. A Correlation Between Clinical and Chest Radiographic Diagnosis of Pneumonia in Nigerian Children. Adv Biores. $2011 ; 2(2): 18-21$

30. Bénet T, Sylla M, Messaoudi M, Sánchez Picot V, Telles JN, Diakite AA et al. Etiology and Factors Associated with Pneumonia in Children under 5 Years of Age in Mali: A Prospective Case-Control Study. PLoS ONE. 2015;10(12):e0145447.

31. Cabre M, Bolivar I, Pera G, Pallares R. Pneumonia Study Collaborative Group. Factors influencing length of hospital stay in community-acquired pneumonia: 
a study in 27 community hospitals. Epidemiol Infect. 2004;132(5):821-9.

32. UR Medicine. Highland Hospital. Average Length of Stay. Available at: https:// www.urmc.rochester.edu/highland/quality-of-care/pneumonia/pneu_stay.aspx Accessed on January 10, 2016

33. Pfuntner A, Wier LM, Steiner C. Costs for hospital stays in the United States, 2010. Healthcare Cost and Utilization Project. 2013; 146, 1-11. Available at: http:// www.hcup-us.ahrq.gov/reports/statbriefs/sb146.pdf Accessed on January 10, 2016.

34. Vieira K. Improving abnormal result. Special Report. 2011;(Vol issue missing):1-56.

35. Waugh DJ, Wilson C. The interleukin-8 pathway in cancer. Clin Cancer Res. 2008;14(21):6735-41.

36. Nelson JM, ChillerTM, Powers JH, Angulo FJ. "Fluoroquinolone-resistant Cam- pylobacter species and the withdrawal of fluoroquinolones from use in poultry: a public health success story. Clin Infect Dis. 2007;44(7):977-80.

37. Shah P, Giudice JC, Griesback R, Morley TF, Vasoya A. The newer guidelines for the management of community-acquired pneumonia. J Am Osteopath Assoc. 2004;104(12):521-6

38. Stupka JE, Mortensen EM, Anzueto A, Restrepo MI. Community-acquired pneumonia in elderly patients. Aging Health. 2009;5(6):763-74

39. (Author name ??)Should Azithromycin No Longer Be Considered a Drug of Choice for Community-Acquired Pneumonia Because of Its Potential to Cause Cardiovascular Death? (2013). Can J Hosp Pharm. 2013;66(5):328-31.

40. Martinez FJ. Monotherapy versus dual therapy for community-acquired pneumonia in hospitalized patients. Clin Infect Dis. 2004;38(Supplement 4):S328-40. 